Progress in Nuclear Science and Technology

Volume 6 (2019) pp. 217-220

\title{
ARTICLE
}

\section{Investigation of activation range for self-shielded PET cyclotron}

\author{
Shohei Iwai ${ }^{\mathrm{a}^{*}}$, Fumiyoshi Nobuhara ${ }^{\mathrm{a}}$, Masahiro Tanaka ${ }^{\mathrm{b}}$ and Naoki Nagasawa ${ }^{\mathrm{c}}$ \\ ${ }^{a}$ Tokyo Nuclear Services Co.,LTD, Sorimachi Bldg., 1-3-5, Taito, Taito-ku, Tokyo, Japan; ${ }^{b} J F E$ Engineering Corporation, 2-1, \\ Suehiro-cho, Tsurumi-ku, Yokohama, Japan: ${ }^{c}$ Mie University Hospital, 2-174, Edobashi, Tsu-shi, Mie, Japan
}

\begin{abstract}
In decommissioning of PET cyclotrons, it is important to evaluate the amount of activated materials and the depth range of activation in order to reduce the disposal cost for radioactive materials. For typical self-shielded PET cyclotrons, it has been reported that the activation of materials surrounding self-shields is negligible, based on a result of the measurements. Focusing on the evaluation of activation range for the self-shielded PET cyclotron in Mie University Hospital using PHITS code and DCHAIN-SP code, we calculated the radioactivity of the concrete samples obtained by core boring and compared the calculated radioactivity with the measured radioactivity (measured by Ge semiconductor detector) at the same boring point. In the case of the concrete sample in front wall of ${ }^{18} \mathrm{O}$ water target, where the radioactivity was expected to be the highest in the self-shields, the results of the calculated radioactivity of ${ }^{54} \mathrm{Mn}$ and ${ }^{60} \mathrm{Co}$ were in good agreement with the results of the measured radioactivity to within a factor $(\mathrm{C} / \mathrm{M})$ of 1.2-1.9. These good agreements suggest that calculated radioactivity is sufficiently accurate to evaluate the depth range of activation. Therefore, we conclude that the activation of materials in the outer side of the self-shields is negligible as shown in the calculated results, as well as previously shown in the measurement.
\end{abstract}

Keywords: activation; self-shielded PET cyclotron; decommissioning; radioactivity; Monte-Carlo; PHITS; DCHAIN-SP

\section{Introduction}

PET cyclotron components and the surrounding concrete structures become activated by protons and neutrons in operating the cyclotron. In decommissioning of PET cyclotrons, it is important to evaluate the amount of activated materials and the depth range of activation in order to reduce the disposal costs for radioactive materials (for example, the clearance radioactivity level for ${ }^{60} \mathrm{Co}$ is set to $0.1 \mathrm{~Bq} / \mathrm{g}$ ). For typical self-shielded PET cyclotrons, it has been reported that the activation of materials surrounding self-shields is negligible, based on a result of the measurements with $\mathrm{Au}$ foils, TLDs, and dosimeters [1]. We focus on the evaluation of an activation range for the self-shielded PET cyclotron by calculation.

\section{Materials and methods}

\subsection{Specification}

The PET cyclotron in Mie University Hospital is self-shielded cyclotron IBA CYCLONE 10/5, and the specific design of the facility was performed by JFE Engineering Corporation. The cyclotron can accelerate negatively charged hydrogen and deuterium ions to 10
$\mathrm{MeV}$ and $5 \mathrm{MeV}$ respectively. In Mie university Hospital, ${ }^{18} \mathrm{~F},{ }^{11} \mathrm{C},{ }^{13} \mathrm{~N}$ were produced via ${ }^{18} \mathrm{O}(\mathrm{p}, \mathrm{n}){ }^{18} \mathrm{~F}$, ${ }^{14} \mathrm{~N}(\mathrm{p}, \alpha){ }^{11} \mathrm{C},{ }^{16} \mathrm{O}(\mathrm{p}, \alpha){ }^{13} \mathrm{~N}$ reactions respectively, but according to the operation record of the cyclotron, more than $90 \%$ of the integrated current was for producing ${ }^{18} \mathrm{~F}$. The target current was $30 \mu \mathrm{A}$ on average.

\subsection{Calculation}

\subsubsection{Neutron flux distribution in cyclotron vault}

We calculated the neutron flux distribution around the cyclotron using PHITS-2.64 [2] code with TENDL-2014 [3] cross-section library for protons and JENDL-4.0 [4] cross-section library for neutrons.

The major components of the cyclotron (targets, a dee, a vacuum chamber, a yoke, electromagnets, and sector magnets) and the surrounding concrete structures (a movable self-shield, a fixed self-shield, walls, a floor with pits, and a ceiling) were modelled. The self-shields were about $110 \mathrm{~cm}$ thick and covered with $9 \mathrm{~mm}$-thick iron frames, and the concrete contained polyethylene and boron carbide. Besides, core boring samples of concrete structures were modelled in the actual size at the sampling position. The results of the calculation are provided for comparing the measured radioactivity to verify the accuracy of the calculation. Figure 1 shows

*Corresponding author. Email: iwai@tokyo-nucl.co.jp 


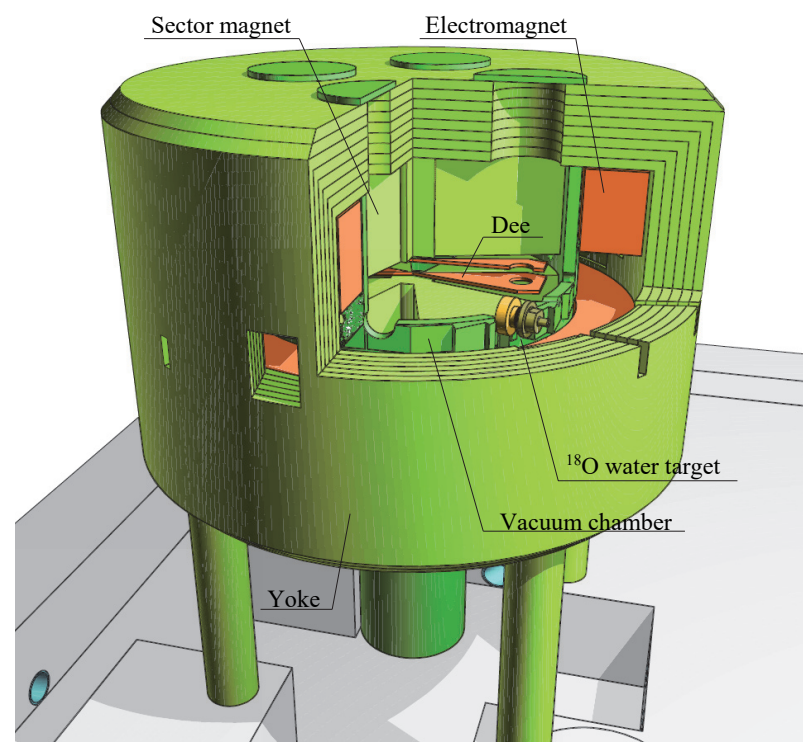

Figure 1. Calculation geometry of the PET cyclotron (cutaway view).

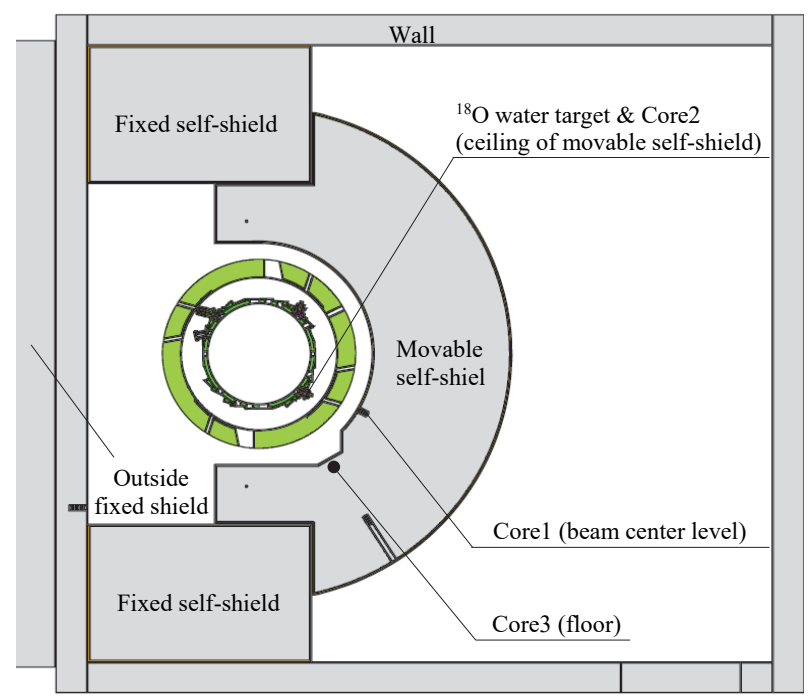

Figure 2. Calculation geometry in the PET cyclotron vault at beam center level. The size of the vault was approximately $5400 \mathrm{mmW} \times 5000 \mathrm{mmD} \times 4000 \mathrm{mmH}$.

the calculation geometry of the cyclotron (cutaway view) and Figure 2 shows the calculation geometry in the cyclotron vault at the height of the beam center.

We assumed that the beam losses except for the target could be ignored and the operating time was all for producing ${ }^{18} \mathrm{~F}$ since more than $90 \%$ of the integrated current was for producing ${ }^{18} \mathrm{~F}$. In the calculation, the incident source was set to $10 \mathrm{MeV}$ proton beam heading for ${ }^{18} \mathrm{O}$ water target and was set to $1 \mathrm{~cm}$ in front of the vacuum foil which was positioned in more front side (cyclotron side) than the target.

It is important that material composition of the surrounding concrete structures is accurate, because the amount of trace elements directly affects the radioactivity of materials. In the calculation, the main compositions analyzed by an XRF (X-ray fluorescence)
Table 1. Composition and mass density of concrete structures. (In the calculation, composition of self-shields was set to below adding boron and carbon.)

\begin{tabular}{cccc}
\hline $\begin{array}{c}\text { Structure } \\
\left(\mathrm{g} / \mathrm{cm}^{3}\right)\end{array}$ & $\begin{array}{c}\text { Self-shield } \\
1.66\end{array}$ & $\begin{array}{c}\text { Wall } \\
2.06\end{array}$ & $\begin{array}{c}\text { Floor } \\
2.12\end{array}$ \\
\hline Element & $\left(\times 10^{24} \mathrm{~cm}^{-3}\right)$ & $\left(\times 10^{24} \mathrm{~cm}^{-3}\right)$ & $\left(\times 10^{24} \mathrm{~cm}^{-3}\right)$ \\
$\mathrm{H}$ & $3.87 \times 10^{-2}$ & $4.96 \times 10^{-3}$ & $7.94 \times 10^{-3}$ \\
$\mathrm{O}$ & $2.24 \times 10^{-2}$ & $3.75 \times 10^{-2}$ & $3.83 \times 10^{-2}$ \\
$\mathrm{Na}$ & $2.91 \times 10^{-4}$ & $6.92 \times 10^{-4}$ & $8.98 \times 10^{-4}$ \\
$\mathrm{Mg}$ & $1.77 \times 10^{-4}$ & $3.16 \times 10^{-4}$ & $4.86 \times 10^{-4}$ \\
$\mathrm{Al}$ & $1.13 \times 10^{-3}$ & $1.94 \times 10^{-3}$ & $3.16 \times 10^{-3}$ \\
$\mathrm{Si}$ & $6.03 \times 10^{-3}$ & $1.34 \times 10^{-2}$ & $1.17 \times 10^{-2}$ \\
$\mathrm{P}$ & $7.19 \times 10^{-6}$ & $9.05 \times 10^{-6}$ & $2.00 \times 10^{-5}$ \\
$\mathrm{~S}$ & $8.82 \times 10^{-5}$ & $6.10 \times 10^{-5}$ & $7.56 \times 10^{-5}$ \\
$\mathrm{~K}$ & $1.66 \times 10^{-4}$ & $2.78 \times 10^{-4}$ & $7.17 \times 10^{-4}$ \\
$\mathrm{Ca}$ & $4.11 \times 10^{-3}$ & $3.37 \times 10^{-3}$ & $3.33 \times 10^{-3}$ \\
$\mathrm{Sc}$ & $1.18 \times 10^{-7}$ & $1.71 \times 10^{-7}$ & $3.12 \times 10^{-7}$ \\
$\mathrm{Ti}$ & $2.24 \times 10^{-5}$ & $4.34 \times 10^{-5}$ & $7.90 \times 10^{-5}$ \\
$\mathrm{Mn}$ & $9.59 \times 10^{-6}$ & $2.54 \times 10^{-5}$ & $1.63 \times 10^{-5}$ \\
$\mathrm{Fe}$ & $2.55 \times 10^{-4}$ & $5.58 \times 10^{-4}$ & $6.94 \times 10^{-4}$ \\
$\mathrm{Co}$ & $1.29 \times 10^{-7}$ & $1.77 \times 10^{-7}$ & $1.91 \times 10^{-7}$ \\
$\mathrm{Cs}$ & $1.05 \times 10^{-8}$ & $3.17 \times 10^{-8}$ & $2.21 \times 10^{-8}$ \\
$\mathrm{Eu}$ & $6.58 \times 10^{-9}$ & $8.16 \times 10^{-9}$ & $9.24 \times 10^{-9}$ \\
\hline
\end{tabular}

analyzer and the trace elements analyzed by an ICP-MS spectrograph were used.

In addition, it is also important that water content of the surrounding concrete structures is accurate because water content greatly affects the neutron transport. In the calculation, the water content analyzed by Japanese Industrial Standards method [5] were used. Table 1 shows the composition and mass density of the concrete structures.

\subsubsection{Radioactivity of materials}

We calculated the radioactivity of the core boring samples using DCHAIN-SP 2001 [6] code with the neutron spectra obtained by PHITS code at the same core boring point. As for the cyclotron components, we did not calculate these radioactivity because the cyclotron itself would be apparently radioactive. In the calculation, material compositions of the surrounding concrete structures were the same as the calculation with PHITS code. The irradiation time was set to the actual operating period (about 9 years), and the cooling time was set to the actual cooling period (about 3 years) until the measurement date for the core boring samples. The irradiation time steps and the irradiation flux of each time step were based on the monthly integrated currents.

\subsection{Measurement}

The core boring samples were sliced in $2 \mathrm{~cm}$ thick, and the radioactivity of each sample pulverized with a stamp mill was measured by a Ge semiconductor detector. The measurement time was $3000 \mathrm{sec}$ for each sample and the detection limit was approximately $10^{-3}$ to $10^{-2} \mathrm{~Bq} / \mathrm{g}$ although it was different from a nuclide to another. 


\section{Results and discussion}

\subsection{Neutron flux distribution in cyclotron vault}

Figure 3 shows the result of the neutron flux distributions for fast neutrons and thermal neutrons around the cyclotron at the height of the beam center with $30 \mu \mathrm{A}$. The energy range of fast neutron and thermal neutron are set to approximately $1-10 \mathrm{MeV}$ and 0.00001-0.4 eV respectively. The fast neutron flux was naturally high at the target and slightly higher at the place where the fast neutrons went through the ports of the yoke and the vacuum chamber. The thermal neutron flux inside the yoke was higher around the ${ }^{18} \mathrm{O}$ water target because of the effect of the neutron moderation in the target itself, and in the atmospheric air inside the self-shields, there was no place where the thermal neutron flux was locally higher because the thermal neutrons were produced in various places inside the


Figure 3. Neutron flux distribution for thermal neutron and fast neutron around the PET cyclotron, and both scales of neutron flux are different from each other. The models of the yoke and the vacuum chamber show only the outlines of them. The size of the plotting area is $2000 \mathrm{mmW} \times 2000 \mathrm{mmD}$. self-shields. Since the amount of neutron flux was large and the neutrons reached deeply into the cyclotron components and the movable self-shield, the cyclotron itself naturally became activated and it was estimated that the surrounding concrete structures (at least the movable self-shield) became activated.

\subsection{Radioactivity of materials}

Figure 4 shows the comparison of the calculated radioactivity and the measured radioactivity in the core boring samples. Overall, in the calculation, the nuclides of ${ }^{54} \mathrm{Mn},{ }^{60} \mathrm{Co},{ }^{134} \mathrm{Cs},{ }^{152} \mathrm{Eu},{ }^{154} \mathrm{Eu}$ were mainly produced in the calculation via ${ }^{54} \mathrm{Fe}(\mathrm{n}, \mathrm{p}){ }^{54} \mathrm{Mn},{ }^{59} \mathrm{Co}(\mathrm{n}, \gamma){ }^{60} \mathrm{Co}$, ${ }^{133} \mathrm{Cs}(\mathrm{n}, \gamma){ }^{134} \mathrm{Cs},{ }^{151} \mathrm{Eu}(\mathrm{n}, \gamma){ }^{152} \mathrm{Eu},{ }^{153} \mathrm{Eu}(\mathrm{n}, \gamma){ }^{154} \mathrm{Eu}$ reactions respectively, while in the measurement, only ${ }^{54} \mathrm{Mn}$ and ${ }^{60} \mathrm{Co}$ were detected and the other nuclides were below the detection limits. Those reactions except for ${ }^{54} \mathrm{Fe}(\mathrm{n}, \mathrm{p}){ }^{54} \mathrm{Mn}$ are mainly induced by thermal neutrons but ${ }^{54} \mathrm{Fe}(\mathrm{n}, \mathrm{p}){ }^{54} \mathrm{Mn}$ is mainly brought about by fast neutrons.

The results of the calculated radioactivity of ${ }^{60} \mathrm{Co}$ were in good agreement with the results of the measured radioactivity to within a factor (C/M: Calculation result/Measurement result ratio) of 0.8-1.9 in all core samples. For the iron frame covering the movable self-shield (core1), the calculated radioactivity of ${ }^{54} \mathrm{Mn}$ was also in good agreement with the measured radioactivity to within a factor $(\mathrm{C} / \mathrm{M})$ of 1.2 . Therefore, we judged that the neutron behavior was accurately simulated by PHITS code.

In addition, regarding the radioactivity trends of these nuclides, the results of core1 and core2 (self-shield: including boron carbide) tended to decrease as the depth increased without build-up effect. However, the results of core3 (floor: not including boron carbide) tended to increase within a shallow part with build-up effect. In general, build-up effect appears where fast neutrons are dominant. In the case of this facility, because of the boron carbide in the self-shields, it was not simple whether build-up effect would appear. Judging from the tendency of the radioactivity obtained by the calculation, it is believed that the radioactivity of these nuclides cannot be detected in the deeper part.

The results of the calculated radioactivity were in good agreement with the results of the measured radioactivity. These good agreement suggests that the calculated radioactivity using PHITS code and DCHAIN-SP code is sufficiently accurate to evaluate the depth range of activation. Therefore, the activation of materials in the outer side of the self-shields is negligible as shown in the calculated results, as well as previously shown by the measurements.

In decommissioning of this facility, removing the surface of the surrounding concrete structures has been finished. Based on the results of the calculation and the measurement, the actual removing depth for the walls and the self-shields were about $10 \mathrm{~cm}$ thick, and for the floor, it was about $40 \mathrm{~cm}$ thick from the floor level because of the pits on the floor. 

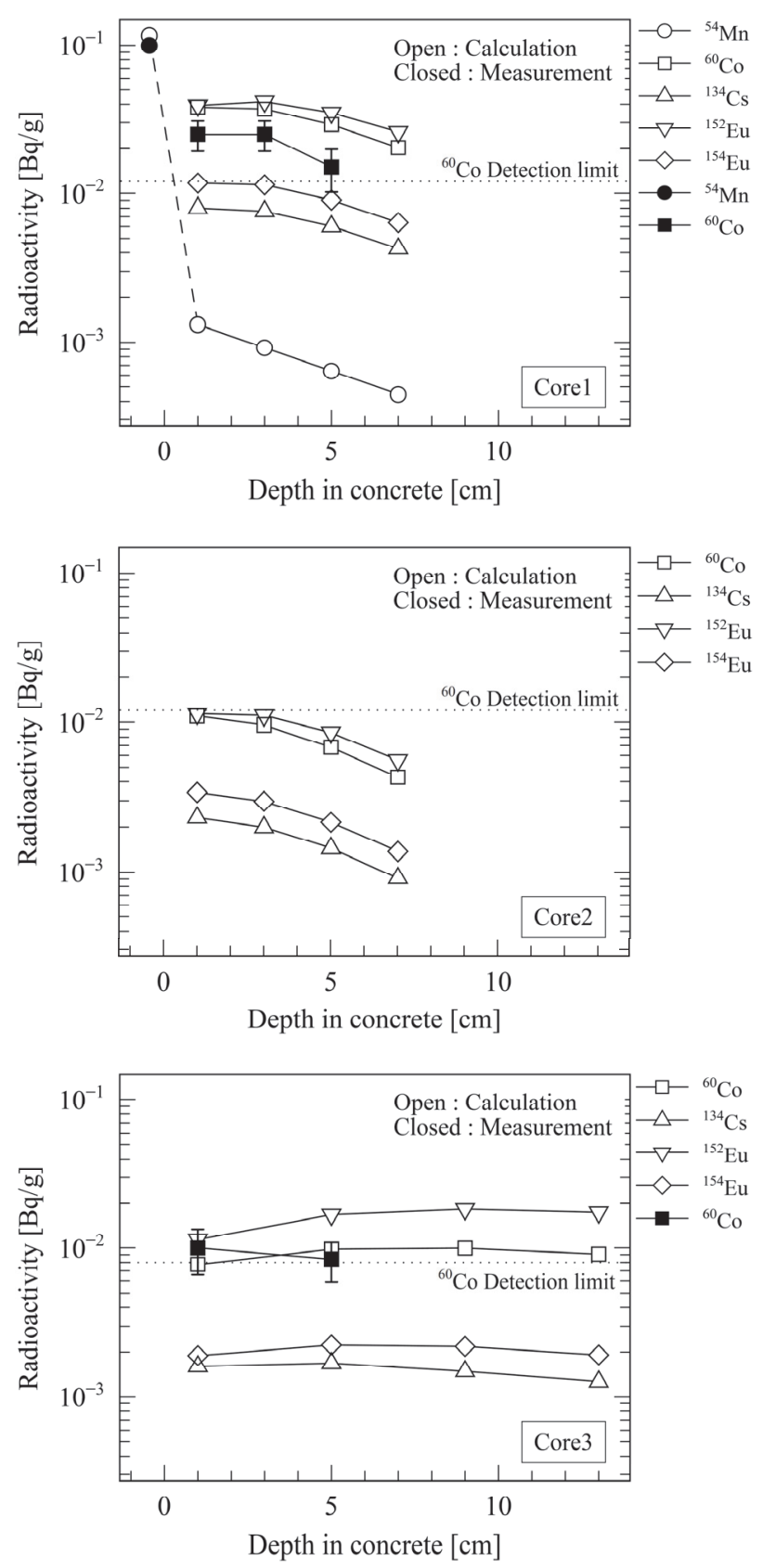

Figure 4. Comparisons of the calculated radioactivity and the measured radioactivity (with error bar) in the core boring sample1-3. Negative depth in the case of core1 indicates that the point is in the iron frame covering self-shields. In addition, detection limits of ${ }^{60} \mathrm{Co}$ were also shown in the figures for reference. The detection limits fluctuated because of the large deviation occurred by low level radioactivity.

\section{Conclusion}

Focusing on the self-shielded PET cyclotron in Mie University Hospital, we evaluated the depth range of activation by calculation using PHITS code and DCHAIN-SP code. The results of the calculated radioactivity for ${ }^{60} \mathrm{Co}$ and ${ }^{54} \mathrm{Mn}$ were in good agreement with the results of the measured radioactivity to within a factor $(\mathrm{C} / \mathrm{M})$ of $0.8-1.9$ in the core boring samples. These good agreements suggest that the calculated radioactivity is sufficiently accurate to evaluate the depth range of activation.

We conclude that the activation of materials in the outer side of the self-shields is negligible as shown in the calculated results.

\section{Acknowledgements}

The authors wish to thank Prof. K. Masumoto for the helpful comments.

\section{References}

[1] K. Masumoto, H. Iiduka, S. Sato, K. Kuga, T. Fujibuchi, M. Sasaki, T. Fukumura, H. Nakamura, and A. Toyoda, Effectiveness of self-shielding type cyclotrons, Prog. Nucl. Sci. Technol. vol 4 (2014), pp. 223-227.

[2] T. Sato, K. Niita, N. Matsuda, S. Hashimoto, Y. Iwamoto, S. Noda, T. Ogawa, H. Iwase, H. Nakashima, T. Fukahori, K. Okumura, T. Kai, S. Chiba, T. Furuta and L. Sihver, Particle and Heavy Ion Transport Code System PHITS, Version 2.52, J. Nucl. Sci. Technol. 50:9, 913-923 (2013).

[3] A.J. Koning, D. Rochman, S. van der Marck, J. Kopecky, J. Ch. Sublet, S. Pomp, H. Sjostrand, R. Forrest, E. Bauge, H. Henriksson, O. Cabellos, S. Goriely J. Leppanen, H. Leeb, A. Plompen and R. Mills, TENDL-2014: TALYS-based evaluated nuclear data library, www.talys.eu/tendl-2014.html

[4] K. Shibata, O. Iwamoto, T. Nakagawa, N. Iwamoto, A. Ichihara, S. Kunieda, S. Chiba, K. Furutaka, N. Otuka, T. Ohsawa, T. Murata, H. Matsunobu, A. Zukeran, S. Kamada, and J. Katakura, JENDL-4.0: A New Library for Nuclear Science and Engineering, J. Nucl. Sci. Technol. 48(1), 1-30 (2011).

[5] JIS A 1125. Methods of test for moisture content of aggregate and surface moisture in aggregate by drying.

[6] T. Kai, F. Maekawa, K. Kosako, Y. Kasugai, H. Takada, and Y. Ikeda, DCHAIN-SP 2001:High Energy Particle Induced Radioactivity Calculation Code, JAERI-Data/Code 2001-016, 82 (2001). 